\title{
Model Based Controller Design for Hydrogen Fuel Cell Systems
}

\author{
K.K.T. Thanapalan ${ }^{\#}$, G.C. Premier, A.J. Guwy \\ \# Sustainable Environment Research Centre (SERC), \\ Renewable Hydrogen Research \& Demonstration Centre, University of Glamorgan, \\ Baglan Energy Park, Baglan, Port Talbot, SA12 7AX, UK \\ Phone/Fax number: +44(0)1639 814510,e-mail: kthanapa@glam.ac.uk
}

\begin{abstract}
In this paper, fuel cell system modelling alongside controller development for performance improvements, are investigated. Essentially and in general terms there are two approaches to modelling; black box modelling and detailed dynamic modelling. This work addresses both modelling approaches. These models are then used for hydrogen fuel cell (FC) controller development for improved system performance. A fuzzy-PID hybrid controller has been designed and tested and the results indicate that the fuzzy-PID hybrid control strategy can improve the system's performance significantly.
\end{abstract}

\section{Key words}

Modelling, Hybrid control, Fuel cell, Controller Design

\section{Introduction}

Fuel cell technologies have been identified as an area of significance in providing solutions to the problems of meeting increasing renewable energy demands. Mitigation of environmental pollution and providing energy shortage routes has led to fuel cells being considered as elements of alternative energy systems; capitalizing on high efficiencies and low emissions. A fuel cell is an electrochemical energy conversion device which may convert hydrogen and oxygen into water and in the process produces electricity. Fuel cells are able to provide large amounts of current and hence power, with the thermodynamic requirement being the appropriate flow of reactants. It is this supply of reactants which presents one of the several challenges encountered by fuel cell system investigators [1]. There are several types of fuel cells, each using a different chemistry. The Polymer Electrolyte membrane (PEM) fuel cell is commonly used to power vehicles.

The performance of fuel cells and the vehicle applications they are embedded into depends on a delicate balance of the correct temperature, humidity, reactant pressure, purity and flow rate. Thus, it is clear that good performance of the fuel cell system is closely related to the efficacy of the control used. For practical applications, accurate fuel cell models play a key role in controller design and power management, so the study of control oriented models is a critical first step for the understanding of system behaviour, and for subsequent design and analysis of model based control systems [2].
This paper investigates fuel cell system modelling alongside controller development for performance improvements. A variety of literature has been published concerning various aspects of fuel cell system modelling, dynamics and operation. Broader details of the subject can be found in various reports, which summarise the modelling aspects and the problems experienced with fuel cells. These reports also suggest some technical solutions and analysis methods for some of the problems [3]. However, in general there are two types of models which have been proposed to investigate fuel cell technology via simulation. The approaches of these models are: detailed lumped parameter dynamic models; and black-box models based on system identification. The latter commonly expresses as NARX (Nonlinear Auto Regressive with eXogenous input) or ARMAX (Auto Regressive Moving Average with eXogenous input) equations. This work addresses both modelling approaches by presenting an ARMAX model for the black-box modelling approach and a detailed mechanistic model for the dynamic modelling approach.

\section{Fuel Cell System ARMAX Model}

In order to develop control strategies for fuel cell reactant flows, it is necessary to have a model for the fuel cell systems. From a system viewpoint, hydrogen is an input variable and is fed at an adjustable flow rate $N_{H}$. Oxygen is also an input and can be represented by $N_{A}$ where a fuel cell uses the oxygen content of air. Voltage and current are then considered the system outputs. Franklin et al [4] represent this as a standardised MIMO system. Taking this view into consideration in this paper, a cross coupled block representation of the relationship has been formulated as shown in Figure 1, with blocks $G_{i}$ where, $i=1 \ldots 4$ describing the relationship between the outputs $I_{c}$ and $V_{c}$, and inputs $N_{A}$ and $N_{H}$, where $R$ represents the internal cell resistance. The overall stack model can be expressed as follows:

$$
\begin{aligned}
& V_{C}=G_{2} N_{A}+G_{4} N_{H}+R I_{C} \\
& I_{C}=G_{1} N_{A}+G_{3} N_{H}
\end{aligned}
$$

Equations (1) and (2) will now form the basis for the proceeding system identification methodology and design of controllers. 


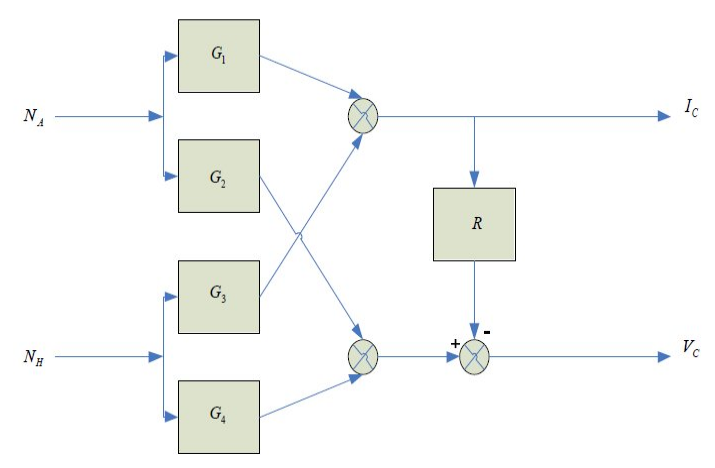

Figure.1. MIMO representation of fuel cell

Considering the relationship between the oxygen flow and the voltage of the fuel cell, by assuming hydrogen flow $N_{H}$, to be constant. The following ARMAX model is derived to describe the dynamics between the oxygen flow $N_{A}$ and voltage $V_{C}$.

$$
\begin{aligned}
& A\left(z^{-1}\right) y(K)=Z^{-d} B\left(z^{-1}\right) u(k)+w(k) \\
& A\left(z^{-1}\right)=1+a_{1} z^{-1}+a_{2} z^{-2}+\ldots+a_{\gamma} z^{-\gamma} \\
& B\left(z^{-1}\right)=b_{0}+b_{1} z^{-1}+b_{2} z^{-2}+b_{\beta} z^{-\beta}
\end{aligned}
$$

where $y, u$ and $k$ denotes the system's output, input and the time instant of sampling respectively. $w$ represents the constant disturbance of $N_{A}$. The order of $A$ and $B$ are denoted by $\gamma$ and $\beta$, respectively. Therefore, without loss of generality $a_{0}=1$. In descending order $A\left(z^{-1}\right) y(k)$ defines the auto regression part, where $z^{-1}$ is the backward shift operator and $z^{-h} u(k)$ represents the past output. $y(k-h) ; h=1,2, . . \gamma$; $B\left(z^{-1}\right) u(k)$ denotes the moving average of past inputs, where $z^{-h} u(k)=u(k-h)$. Finally the corresponding transfer function between outputs and inputs in discrete form can be written as;

$$
G\left(z^{-1}\right)=\frac{B\left(z^{-1}\right)}{A\left(z^{-1}\right)}
$$

where $A\left(z^{-1}\right)$ and $B\left(z^{-1}\right)$ are polynomials and given in Equations (4) and (5) respectively.

To include nonlinear and time varying dynamic identification of the fuel cell, the ARMAX model can be expanded to include the recursive lease squares algorithm (RLS), which allows the identification process to predict the system output according to the past information. ARMAX is a linear model, but is non-linearity piecewise, temporally linearized.
Thus, from equations (3) - (5) the estimation of $y(k)$ is described as follows;

where

$$
\hat{y}(k)=\phi^{T}(k-1) \cdot \hat{\theta}(k-1)
$$

$$
\begin{array}{r}
\phi^{T}(k-1)=[-y(k-1)-y(k-2), \cdots \\
-y(k-\gamma) \mu(k-d) \mu(k-d-1), \cdots \\
\cdots \mu(k-d-\beta)]
\end{array}
$$

$$
\hat{\theta}^{T}=\left[\hat{a}_{1}, \hat{a}_{2}, \cdots, \hat{a}_{\gamma}, b_{0}, b_{1}, \cdots, \hat{b}_{\beta}\right]
$$

After step $k$ the new output is measured and a new set of parameters are obtained by using the following equations;

$$
\begin{gathered}
\hat{\theta}(k)=\hat{\theta}(k-1)+K(k)\left[y(k)-\phi^{T}(k-1) \hat{\theta}(k-1)\right] \\
K(k)=P(k-1) \theta(k-1) \times q^{-1}
\end{gathered}
$$

where $K(k)$ is the estimation gain which brings the relative information of new measurements to update the parameter estimation.

where,

$$
q=\left[\lambda+\phi^{T}(k-1) P(k-1) \phi(k-1)\right]
$$

and

$$
P(k)=\left[I-K(k) \phi^{T}(k-1)\right] \frac{P(k-1)}{\lambda}
$$

$P(k)$ is the covariance matrix which characterises the difference between the estimated and actual values where initially $P(0)$ is chosen to be a large value.

The coefficient $\lambda$ is called the forgetting factor which changes the importance of new information to old and has a range of $0<\lambda<1$

\section{Fuel Cell System Dynamic Model}

Dynamic models of a PEM fuel cell system may contain four interacting sub-systems; cathode/anode mass flow, membrane hydration, and stack voltage. In this paper, a brief summary of a PEM fuel cell system dynamic model that is suitable for control study is presented. Details of the model can be found in [1]. 


\subsection{Cathodelanode mass flow model}

Applying the principle of conservation of mass the governing equations of cathode and anode flow can be derived as follows;

$$
\dot{m}=W_{\text {in }}-W_{\text {out }}
$$

where $W_{\text {in }}$ is mass flow rate of gas increase including the mass flow rate of gas entering the electrode and mass flow rate of gas generated in reaction; $W_{\text {out }}$ is mass flow rate of gas decrease including mass flow rate of gas departing on the electrode and mass flow rate of gas reacted. The units for mass flow are $k g . s^{-1}$, these equations predict the gas flow behaviour and pressure inside the cathode/anode. To derive these expressions for the mass flow subsystem the following assumptions are made; ideal gas law is applicable to all gases; the temperature in the fuel cell stack is constant; and the cathode/anode flow temperature is the same as the fuel cell stack.

\subsection{Hydration Model}

The mass flow of vapour across the membrane $W_{v, m b r}$ is calculated using mass transport principles and membrane properties [1], [3]

$$
W_{v, m b r}=M_{v} A_{f_{c}} n\left(\frac{n_{d} i}{F}-D_{w} \frac{c_{v, c a}-c_{v, a n}}{t_{m}}\right)
$$

where $n$ is number of cells, $n_{d}$ is electro-osmotic coefficient, $D_{w}$ is diffusion coefficient, $A_{f c}$ is cell active area and $M_{v}$ is vapour molar mass.

\subsection{Stack Voltage Model}

The fuel cell voltage is calculated by subtracting the fuel cell losses or overvoltages from the fuel cell open circuit voltage, $E$, and is given by

$$
v_{f c}=E-v_{a c t}-v_{o h m}-v_{c o n}
$$

The total stack voltage can be calculated by multiplying the cell voltage by the number of cells of the stack,

i.e., $\quad v_{s t}=n \times v_{f c}$

where $E$ is the fuel cell open-circuit voltage and is the maximum possible reversible voltage; $v_{a c t}$ represents the activation overpotential at the electrodes; $v_{\text {ohm }}$ represents the ohmic overpotential caused by electrical and ionic conduction loss; $v_{\text {con }}$ represents the concentration overpotential caused by mass transport limitations of the reactants to the electrodes. Each of these terms is modelled as follows:

$$
\begin{aligned}
& E=-\frac{G^{0}(T)}{2 F}+\frac{R T}{2 F} \ln \left(\frac{p_{\mathrm{H}_{2}} p_{\mathrm{O}_{2}}}{p_{\mathrm{H}_{2} \mathrm{O}}}\right) \\
& v_{\text {act }}=-\left[\xi_{1}+\xi_{2} T+\xi_{3} T \ln \left(C_{\mathrm{O}_{2}}\right)+\xi_{4} T \ln \left(i_{F C}\right)\right] \\
& v_{\text {ohm }}=i_{F C}\left(R_{e}+R_{\text {proton }}\right) \\
& v_{\text {con }}=-B \ln \left(1-\frac{i}{i_{\text {max }}}\right)
\end{aligned}
$$

where $\xi_{i}, R_{e}$ and $B$ are adjustable parameters. Including these parameters, the model contains several adjustable parameters. The value of these parameters cannot be determined accurately, and only the ranges of these parameters can be estimated. Parameter optimisation methods can be used to make the model represent the real fuel cell system acceptably.

So far, an ARMAX model and a detailed dynamic model has been established. These models are then used for the controllers' developments to improve system performance. In the following sections of the paper discusses results from the controller developments..

\section{Controller Design}

There are many different type of control strategies developed to improve the performance of the fuel cell system. For example, a Fuzzy control strategy is developed in [5] to improve the performance of the fuel cell system which is based on system error and its rate of variations. In [6] an online self tuning PID controller for PEM fuel cell systems is described. However, from the literature it can be seen that the fuzzy controller design is widely used for performance enhancement in fuel cell systems; see for example, [7], [5], [8], [9], [10]. In [11] for a SOFC, a control strategy using fuzzy logic controller to effect voltage control of the fuel cell at the output of the DC/DC converter is presented. A fuzzy logic based controller is designed, because the cost of the controller design and implementation is relatively low and it has a high performance/cost ratio. The fuzzy logic controller (FLC) is used to overcome inherent disadvantages such as uncontrollably large overshoot and large current ripple. FLC does not need an accurate mathematical plant model [10]. Therefore, it is applicable to a process where the plant model is unknown or ill defined. Fuzzy control is also nonlinear and adaptive in nature and offers robust performance under parameter variations and load disturbances [12], [13].

It is clear that good performance of the fuel cell system is closely related to the kind of control used, so a study of different control alternative is justified [14], [15]. A fuel cell system integrates many components into a power system, which include DC/DC converters, batteries, and 
ultracapacitors in the system; and in cases where the fuel cell is not fed directly with hydrogen, a reformer must also be used. Therefore, there are many control loop schemes, the number of which depends on the configuration of the system. The lower level control takes care of the main control loops inside the fuel cell, which are basically fuel/air feed, humidity, pressure and temperature. The upper level control is in-charge of the whole system, integrating the electrical conditioning, storage and reformer (if required). Many control strategies have been proposed in the literature, ranging from feed-forward control [15], Linear quartertic regulator [16], Neural Networks [17], [18] and Model Predictive Control [19], [20]. Authors in [15] explore the possibility of making use of the known inherent faulttolerant capabilities of Model Predictive Control. Many of these papers focus on the low level control of the fuel cell to fulfil at least one of the three main objectives such as maximum efficiency, voltage control and/or starvation prevention. Furthermore, in [21] a novel scheme to control fuel cell terminal voltage is presented. This control scheme prevents any substantial drop in fuel cell terminal voltage during sudden load change or disturbance. It also discusses topology and control strategy for interfacing an energy storage device like an ultra-capacitor to a fuel cell. This improves the dynamic response of the fuel cell to sudden changes in load, hence enabling a fuel cell powered automobile to accelerate suddenly and also respond in a better manner to sudden change in load conditions. It is argued that, using a bidirectional converter as an interface between fuel cell and ultra-capacitor gives better control over fuel cell voltage during transients. However, these designs are still at the theoretical stage and without real time testing, the validity of these control strategy for real fuel cell system applications are still at investigation. Several analysis tools developed to investigate these types of controllers, for example in [22], are MATLAB based analysis tools for real-time control systems. A few other papers [23], [24] present the experimental study of control strategies, which include parameter estimation and diagnostics. Control and stability enhancement of fuel cells systems [25], [26] is considered by several researchers; in particular investigation of the effect of fuel cells on stability of distribution system is a major research topic in these studies. Reference in [27] describe a simplified fuel-cell model and explains the effect of the mix between fuel cell and gas turbine generation on system stability.

Fuel cells are presently being considered for use in automotive systems to replace the internal combustion engines in buses, vans, and ultimately passenger cars [28]. An auxiliary energy storage device is required for start-up and for storing the energy captured through regenerative braking in electric vehicle applications as present fuel cell technology lacks energy storage capability [29], [30]. A storage unit such as a battery or ultra-capacitors can be integrated into the system in order to overcome the problem. In addition a DC/DC converter is interconnected to the system to boost the fuel cell voltage to the required voltage for the motor controller. The major challenge in designing automotive fuel cell power systems is converting the electrical output from the fuel cell into a usable power and designing a suitable DC/DC converter. Many DC/DC converter topologies with their control strategies are presented in the literature; see for example [29], [30]. An overall fuel cell system configuration within an automotive application is shown in Figure.2.

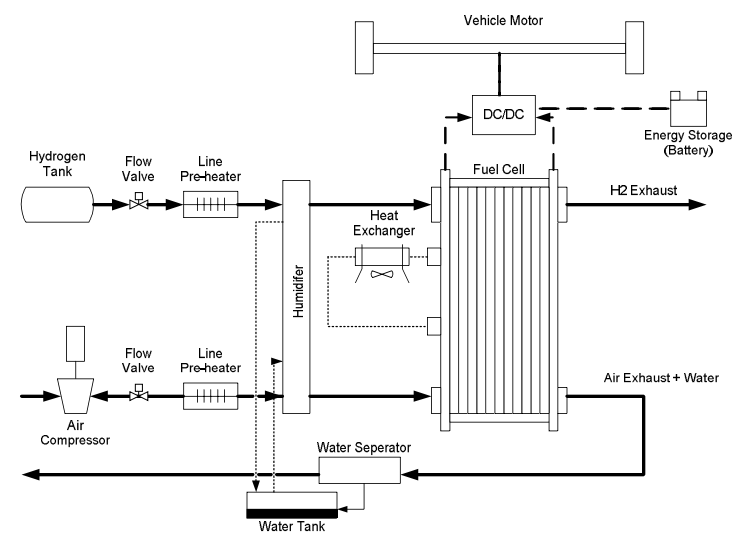

Figure.2 An overall configuration of fuel cell vehicle

The extensive studies in the controller design methods evidence that the fuel cell system control is a very active research area. The research in this area is mainly motivated by the recognition that the current control methods cannot fully meet the desired design requirements on fuel cell system performance, stability, and robustness etc. Any controller design which gives a satisfactory performance on fuel cell system behavior is worth consideration for implementation.

Thanapalan et al. [31] described different types of controller development and implementation for the fuel cell system using a detailed mechanistic model and a PEM Fuel Cell Test station (FCT) to improve the system performances. In contrast, for the same FCT station a black box modelling approach via system identification to develop controllers, is presented in [32]. In this paper we adopted these two approaches together to develop a controller to further improve the system performance.

The underlying idea of our controller design is to use a fuzzy based system to support the operation of a PID controller. It is always a problem in practice to determine a suitable set of parameters for a conventional PID controller. In general, it is not easy to satisfy different design specifications at the same time. To overcome these difficulties we adopt the method described in [32] to obtain the gains of the PID controller. These gains are then used as the initial values of the PID controller in the new Fuzzy-PID hybrid controller design.

PID control is widely used in industry to control many different systems. A PID controller is developed for the fuel cell system using the models described above. The output response is shown in Figure. 3. The solid line, doted and dashed lines indicate the reference voltage, cell output voltage with the manufacturer control $(\mathrm{mfc})$ and 
with PID control respectively. The improvement in system dynamic performance with the PID controller can be clearly seen from Figure 3. We presents the results of PID control against the existing manufacturer control (mfc) (both being closed loop control), with the reference signal (set points). The response results seen in Figure 3 are for the following set point changes (21).

$$
V=0.9 \rightarrow 0.8 \rightarrow 0.4 \rightarrow 0.5 \rightarrow 0.7 \rightarrow 0.5 \rightarrow 0.6 \rightarrow 0.8 \rightarrow 0.9
$$

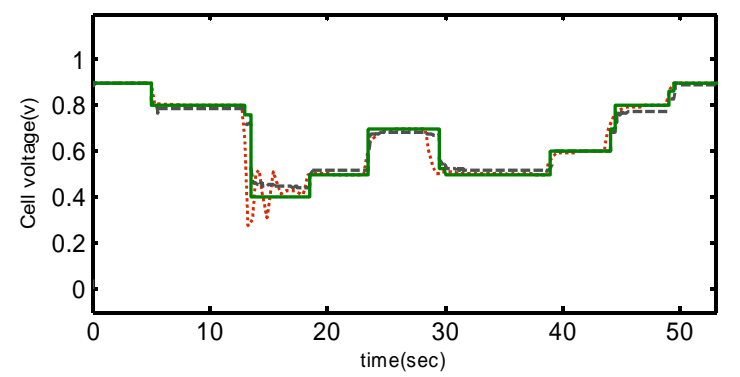

Figure 3. The responses of cell voltage Using a PID controller

$$
\text { (Ref } \longrightarrow \text { PID }---\operatorname{mfc} \cdots \cdots \cdot \text { ) }
$$

The control algorithm will become complex with the fuzzy mechanism on board. A fuzzy control algorithm will become more complex as the control rules increase, and a complex control algorithm will increase the burden on the hardware; especially for a system such as a PEM fuel cell system, with quick dynamic response. Therefore, the fuzzy control algorithm needs to be simplified for real-time implementation. Using the models described above a controller based on fuzzy logic processes which uses the experience of the operator to control the plant, can be synthesised. These kinds of controller designs are presented in [5], [31]. The fuzzy sets generated for the simulation models are then used as the basis for real time implementation. A standardised fuzzy control system with dual inputs (error $e(t)$ and change in error $\dot{e}(t)$ ) and single output (control increment $\Delta u$ ) is used to control the system with $r(t)$ considered as the set point. The controller output $u$ can be obtained by

$$
u(t)=u(t-1)+\Delta u(t)
$$

In this paper we use the fuzzy based system to support the operation of a PID controller. The output response of the Fuzzy-PID hybrid controller is shown in Figure. 4.

The system dynamic performance with the Fuzzy-PID controller is an improvement on that obtained by the PID controller, as can be seen from Figures 4 and 5 . The results indicate that the hybrid control strategy has improved the system performance significantly compared to PID or fuzzy controllers.

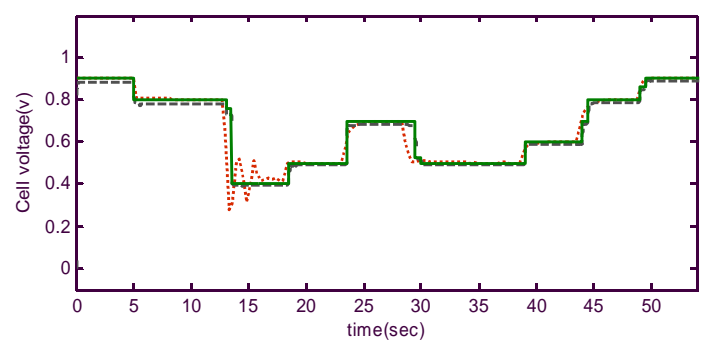

Figure 4. The responses of cell voltage Using a Fuzzy-PID hybrid controller (Ref — Hybrid Control - - $-\mathrm{mfc} \cdot \cdots \cdot . \cdot$.)

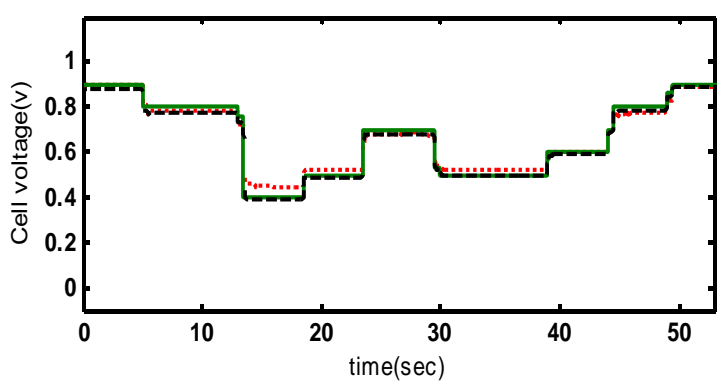

Fig.5. Comparison of simulation responses of cell voltage using a PID and Fuzzy-PID hybrid controllers for set point changes

(Ref — Hybrid Control - - - PID Control ……)

\section{Concluding remarks and Discussion}

In this paper an investigation of fuel cell system modelling, alongside controller development for performance improvements, are carried out. The results indicate that the Fuzzy-PID hybrid control strategy has improved the system performance significantly. Furthermore, it has been observed that, due to complexity and non-linearity of fuel cell system, the mechanistic model with optimized parameters is unable to contain all of the characteristics of the fuel cell system, no matter how accurate the model is. This is due to the fact that during the development of the model, many assumptions and approximations are made, and many nonlinearities and unmeasurable factors are ignored. Therefore, it is recommended that a NARX / ARMAX model can be used in conjunction with the mechanistic model in order to further reduce the errors between mechanistic model and real system (see, Figure. 6)

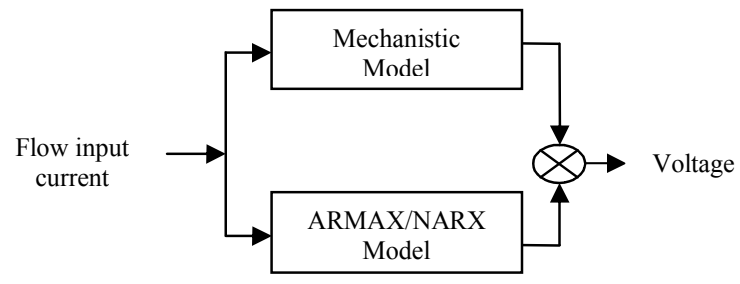

Figure. 6. Hybrid model structure 
If this hybrid model is used to represent the fuel cell system the representation may be more accurate than the single mechanistic model or the single black box model. Future work is now proceeding to expand this strategy to investigate the hybrid modelling approach. This will be followed by extending the work to include an additional optimisation algorithm to adjustable parameters in the mechanistic model be more accurate.

\section{References}

[1] K.K.T.Thanapalan., J.G.Williams., G.P.Liu., D.Rees., Modelling of a PEM Fuel Cell System" In the proc. of IFAC World Congress'08, Seoul, Korea, 2008, pp.46364641

[2] J.Golbert, D.Lewin, "Model-Based Control of Fuel Cells: Regulatory Control", J. of Power Sources, October 2003

[3] K.K.T.Thanapalan., G.P.Liu., J.G.Williams., B.Wang., D.Rees., 'Review and Analysis of Fuel Cell System Modelling and Control', Int. Journal of Computer Aided Engineering and Technology, 2009, vol.1, No.2, pp.145157.

[4] G.F.Franklin., J.D.Powell., N.A.Emami., 'Feedback Control of Dynamic Systems', 2006, $5^{\text {th }}$ Edition, Pearson Prentice Hall.

[5] J.G.Williams., G.P.Liu., S.Chai., D.Rees., "Intelligent control for improvements in PEM fuel cell flow performance", Int. Journal of Automation and Computing, 2008, 05(2), pp145-151

[6] J.G.Williams., G.P.Liu., K.K.T.Thanapalan., D.Rees., "Design and Implementation of On-line Self-Tuning Control for PEM Fuel Cells" In the proc. of EVS-23, Sustainability- The future of Transportation, California, USA, 2007, pp 359-375

[7] Y.Kim., S.Kim., "Electrical modelling and fuzzy logic control of a fuel cell generation system", IEEE Trans Energy Conversion, 2009, vol 14, pp239-244.

[8] S.Tang., G.P.Liu., "Real-time simplified variable universe fuzzy control of PEM fuel cell flow systems", In the proc. of the European Control Conference 2007, Kos, Greece, 2007

[9] J.O.Schumacher., P.Gemmar., M.Denne., M.Zedda., M.Strueder., " Control of Miniature Proton Exchange Membrane Fuel Cell Based on Fuzzy Logic", J.of Power Sources, 2004, vol 129(2), pp143-151.

[10] M.Zhijun, Z.Xinjian, C.Guangyi, "Design and Simulation of fuzzy controller for PEMFCs" In the Proc of IEEE Int Conf on Industrial Technology, 2005, pp220-224

[11] A.Sakhare, A.Davari, A.Feliachi, "Control of Stand Alone Oxide Fuel Cell using Fuzzy Logic", In the Proc of the $35^{\text {th }}$ Southeastern Sym on Sys Theory' 2003, pp473-476, March 2003

[12] F.Jurado, M.Valverde, "Fuzzy logic inverter flux control of fuel cell plants in distributed generation", $11^{\text {th }}$ Int Conf on Harmonics and Quality of Power, 2004

[13] F.Jurado, M.Valverde, "Novel Inverter Flux Control ForFuel Cell Using Fuzzy Logic", In the Proc of $4^{\text {th }}$ Int Conf on Power Electronic and Motion Control, 2004, vol.2, pp714-718

[14] A.Rosich.,V.Puig.,J.Quevedo.,"Fault-Tolerant Constrained MPC of PEM Fuel Cells", IAR Annual Meeting, 2006, pp1-6

[15] J.T.Pukrushpan., A.G.Stefannopoulou., H.Peng., "Control of Fuel Cell Power Systems: Principles, Modelling, and Analysis and Feedback Design", series Advances in Industrial Control, 2004, Springer.

[16] P.Rodatz., G.Paganelli., A.Sciarretta., L.Guzzella., "Optimal power management of an experimental fuel cell/supercapacitor-powered hybrid vehicle", Control Engineering Practice, 2005, vol.13, pp41-53.
[17] P.E.M. Almeida., and M.G.Simoes., "Neural optimal control of PEM fuel cells with parametric CMAC networks", IEEE Trans. on Industry Applications, 2005, vol 41(1), pp 237-245

[18] M.Y.El-Sharkh., A.Rahman., M.S.Alam., "Neural networks-based control of active and reactive power of a stand-alone PEM fuel cell plant", J.of Power Sources, 135, pp88-94, 2004

[19] C.Bordons., A.Arce., A.J. Del Real., "Constrained Predictive Control Strategies for PEM fuel cells", In the Proc. of ACC'06, ACC, Minnesota, USA, 2006.

[20] A.Vahidi., A.G.Stefannopoulou., H.Peng., " Current Management in a Hybrid Fuel Cell Power System: A Model Predictive Control Approach", IEEE Trans. on Control Systems Technology, vol.14(6), 2006.

[21] A.Drolia, P.Jose, N.Mohan "An Approach to Connect Ultracapacitor to Fuel Cell Powered Electric Vehicle and Emulating Fuel Cell Electrical Characteristics using Switched Mode Converter", In the Proc of the $29^{\text {th }}$ IEEE Int Conf of the Industrial Electronics Society 2003,vol.1, pp897-901

[22] A.Cervin, D.Henriksson, B.Lincoln, K.Arzen, "Jitterbug and True time : Analysis Tools for Real-Time Control Systems", $2^{\text {nd }}$ Workshop on Real-Time Tools, Copenhagen, Denmark, August 2002

[23] H.Lee, K.Jeong, B.Oh, "An Experimental study of Controlling Strategies and drive forces for hydrogen fuel cell hybrid vehicles", Int. Jof Hydrogen Energy, Vol 28, pp215-222, 2003

[24] A.Forrai, H.Funato, Y.Yanagita, Y.Kato, "Fuel-cell Parameter Estimation and Diagnostics", IEEE Trans on Energy Conversion, vol 20(3), September 2005

[25] K.Sedghisigarchi, A.Feliachi", "Control of grid-connected fuel cell power plant for transient stability enhancement", In the Proc of IEEE Power Eng Soc, 2002, pp383-388

[26] K.Sedghisigarchi, A.Feliachi, "Dynamic and Transient Analysis of Power Distribution Systems with Fuel CellsPart II: Control and Stability Enhancement", IEEE Trans on Energy Conversion, Vol 19, No2, June 2004

[27] C.Hatziadoniu, A.Lobo, et al "A simplified dynamic model of grid-connected fuel-cell generators", IEEE Trans Power Delivery, vol 17, pp467-473, April 2002

[28] U.G.Bossel, "Solid oxide fuel cells for transportation," In the Proc of the $3^{\text {rd }}$ European SOFC forum, France, 1998.

[29] G.Su, F.Peng, D.Adams, "Experimental Evaluation of a Soft-Switching DC/DC Converter for Fuel Cell Vehicle Applications", In the Proc of the IEEE Int Conf on Power Electronics in Transportation, 2002, pp39-44

[30] M. Marei, S.Lambert, R.Pick, M.Salama, "DC/DC Converters for Fuel Cell Powered Hybird Electric Vehicle" In the Proc of IEEE Int Conf on Vehicle Power and Propulsion, September 2005, pp126-129

[31] K.K.T.Thanapalan., G.P.Liu., J.G.Williams., D.Rees., Fuzzy Controller Development for A PEM Fuel Cell System" In the proc. of UKACC'08, Manchester, UK, 2008

[32] J.G.Williams., G.P.Liu., K.K.T.Thanapalan., D.Rees., “ Design and Implementation of on-line self tuning control for PEM Fuel Cells' The World Electric Vehicle Journal, Vol. 2(4), 2008, pp7-17 